\title{
Interhemispheric asymmetry of climate change projections of boreal winter surface winds in CanESM5 large ensemble simulations
}

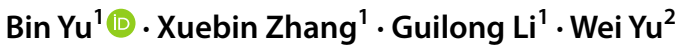

Received: 29 April 2021 / Accepted: 17 January 2022 /Published online: 5 February 2022

(c) Crown 2022

\begin{abstract}
A recent study of global wind power using an ensemble of ten CMIP5 climate simulations indicated an interhemispheric asymmetry of wind power changes over the twentyfirst century, featured by power decreases across the Northern Hemisphere mid-latitudes and increases across the tropics and subtropics of the Southern Hemisphere. Here we analyze future projections of surface mean and extreme winds by means of a single-model initial-condition 50-member ensemble of climate simulations generated with CanESM5, the Canadian model participated in CMIP6. We analyze the ensemble mean and spread of boreal winter mean and extreme wind trends over the next half-century (2021-2070) and explore the contribution of internal climate variability to these trends. Surface wind speed is projected to mostly decrease in northern mid-low latitudes and southern mid-latitudes and increase in northern high latitudes and southern tropical and subtropical regions, with considerable regional variations. Large ensemble spreads are apparent, especially with remarkable differences over northern parts of South America and northern Russia. The interhemispheric asymmetry of wind projections is found in most ensemble members, and can be related to large-scale changes in surface temperature and atmospheric circulation. The extreme wind has similar structure of future projections, whereas its reductions tend to be more consistent over northern mid-latitudes. The projected mean and extreme wind changes are attributed to changes in both externally anthropogenic forced and internal climate variability generated components. The spread in wind projections is partially due to large-scale atmospheric circulation variability.
\end{abstract}

Keywords Future projections $\cdot$ Surface mean and extreme winds $\cdot$ SMILE $\cdot$ CanESM5

Bin Yu

Bin.Yu@ec.gc.ca

1 Climate Research Division, Environment and Climate Change Canada, 4905 Dufferin Street, Toronto, ON M3H 5T4, Canada

2 National Prediction Development, Environment and Climate Change Canada, Dorval, Canada 


\section{Introduction}

Wind power is a sustainable and renewable source of energy that contributes significantly to reduce global greenhouse gas emissions and affects the Earth's climate (e.g., Solomon et al. 2007). Wind energy production depends on weather conditions and is therefore influenced by climate variability and changes, which could alter the spatiotemporal characteristics of wind by means of changes in the background climatological condition and synopticscale variation. Wind power is defined as the kinetic energy of air in motion and mainly depends on wind speed, although it is also influenced by air density. Given that wind power is the cube of wind speed, a small change in wind can have substantial consequences for the wind energy (e.g., Pryor and Barthelmie 2010). For example, a 10\% of wind change could bring about $30 \%$ of wind energy density change. Hence, understanding the influence of climate variability and future climate changes on wind is a crucial aspect in the wind resource study.

Wind speed normally increases with altitude and over open areas without windbreaks. In observational and modeling studies, winds have been examined at various levels and the wind speed profile is usually represented by the theoretical power-law profile (e.g., Hsu et al. 1994; McVicar et al. 2008; Kim and Paik 2015), for example, wind speeds at near-surface levels (typically at $10 \mathrm{~m}$ above the surface) and the free troposphere (such as $850 \mathrm{hPa}$ and $300 \mathrm{hPa}$ ) have been employed in studies of wind trend (e.g., Pryor et al. 2009; Vautard et al. 2010; McVicar et al. 2012; Torralba et al. 2017). Winds at the free atmosphere are considered to reduce the influence of surface geophysical fields so that less uncertainty can be expected in the wind speed estimation. In general, a broadly similar pattern of the wind trend in past few decades can be obtained at various levels, suggesting that the main driver of the wind speed trend tends to be the change in large-scale atmospheric circulation (Torralba et al. 2017).

Wind changes have been extensively investigated on regional and local scales (e.g., reviews of Pryor and Barthelmie 2010, and Wu et al. 2018, and references therein; Karnauskas et al. 2018). These involve studies of surface wind changes in past decades (e.g., Klink 1999; Pryor et al. 2009; McVicar and Roderick 2010; Vautard et al. 2010; McVicar et al. 2010, 2012; Bett et al. 2017; Zeng et al. 2019; Lai et al. 2021; Deng et al. 2021) and future wind projections (e.g.,Pryor and Schoof 2010; Hueging et al. 2012; Kumar et al. 2014; Reyers et al. 2016; Moemken et al. 2018). However, few studies have focused on a global scale. Recently, Karnauskas et al. (2018) performed a global assessment of future changes in wind power using an ensemble of climate simulations from 10 models (one integration for each model) participated in the Coupled Model Intercomparison Project Phase 5 (CMIP5). An interhemispheric asymmetry of wind power changes over the coming century, featured by decreases across the Northern Hemisphere $(\mathrm{NH})$ mid-latitudes and increases across the tropics and subtropics of the Southern Hemisphere ( $\mathrm{SH})$, was found. They also pointed out that the wind power change can be partially explained by established features of global warming, particularly the projected change of temperature gradients related to polar amplification in high latitudes and land amplification in low latitudes.

Climatic extremes, including wind extremes such as extreme wind gusts, also considerably influence human and natural systems. Climate changes in temperature and precipitation extremes have been extensively investigated (e.g., Meehl and Tebaldi 2004; Sillmann et al. 2017; Yu et al. 2019; and references therein). However, less attention has been paid to wind extremes, especially on a global scale. In addition, contributions of internal climate variability to climate changes of mean and extreme temperature and precipitation have been 
found to be comparable to their externally anthropogenic forced counterparts on regional scales (e.g., Deser et al. 2012, 2014; Yu et al. 2020). Whether the interhemispheric asymmetry of future wind changes can be found in climate projections simulated by state-of-theart climate models and to what extent the mean and extreme wind changes are influenced by internal climate variability are important issues that remain to be addressed.

The purpose of this study is to project surface wind over the next half-century and explore the role of internal variability on this projection. We use a 50-member ensemble of climate simulations generated by CanESM5 that is the Canadian model participating in CMIP6. Single-model initial-condition large ensemble (SMILE) simulations enable us to make a robust quantification of projections and to isolate the internal climate variability generated component from the externally forced response (e.g., Wallace et al. 2014; Deser et al. 2014; Kay et al. 2015). We focus on global surface winds in boreal winter when the seasonal mean and variation of wind speed in the NH are stronger than those in other seasons (e.g., Peixoto and Oort 1992). Seasonal means and variations of wind speed are also comparable in the SH in austral summer and winter (Supplementary Fig. S1). Here, we first examine if there is an interhemispheric asymmetry of wind projections in CanESM5 climate change simulations. We then explore how the asymmetry feature is influenced by internal climate variability. In addition, we compare the differences in projected mean and extreme wind changes that are attributed to externally anthropogenic forcing and internal climate variability.

The rest of the paper is organized as follows: Section 2 describes the reanalysis data, CanESM5 model and simulations, and analysis methods employed. Section 3 evaluates the model performance of CanESM5 in simulating surface wind and examines the projected trend of surface wind over the next half-century, inter-member trend variance, forced and internal components of the trend, and contribution of large-scale atmospheric circulation variability on the trend. Section 4 describes the corresponding results as in Section 3 but for extreme wind. In addition, the driving force of air temperature on wind changes is also assessed in Section 3. A summary and discussion are given in Section 5.

\section{Data and methodology}

\subsection{Reanalysis data and data processing}

Daily near-surface wind speeds (U at about $10 \mathrm{~m}$ ) are extracted from the fifth generation of atmospheric reanalysis (ERA5, Hersbach et al. 2020) of the European Centre for MediumRange Weather Forecasts (ECMWF). Only horizontal components of surface winds over land are considered. Ramon et al. (2019) compared surface winds in five state-of-the-art reanalyses and found that ERA5 outperforms the others in reproducing the observed mean and variability of wind on a daily time-scale. Here we use the bias corrected ERA5 data (Lange 2019) and interpolate the data to standard $2.5^{\circ} \times 2.5^{\circ}$ grids to compare with climate model simulations. We also create an extreme wind index (U90) with the percentage of time when daily surface wind speed is above its 90 th percentile. The percentile-based index is derived using 1981-2010 as the base period and applying a 5-day running window. The extreme wind is then examined on a seasonal basis, like previous studies on extreme temperatures (e.g., Sillmann et al. 2013; Yu et al. 2021). We use December-February (DJF) mean U and U90 over 1980-2014 as observed climatological means. Years refer to the January dates throughout this study. 


\subsection{CanESM5 simulations}

Outputs from a large ensemble of historical and climate change forced simulations conducted with CanESM5 are employed. CanESM5 is a fully coupled ocean-atmosphereland-sea ice climate model (Swart et al. 2019, and references therein) developed at the Canadian Centre for Climate Modelling and Analysis (CCCma). It has a horizontal T63 spectral resolution of approximately $2.8^{\circ}$ in the atmosphere and roughly $1^{\circ}$ in the ocean. Detailed descriptions of the model can be found on the website CanESM5-The Canadian Earth System Model version 5-Open by Default Portal (canada.ca). The SMILE simulations we analyzed consist of 50 ensemble members of 251-year integrations over the 1850-2100 period, with slightly different initial conditions for each run in 1850. Each of the simulations is forced by identical historical greenhouse gas concentration, sulfate aerosols, and other observation based radiative forcings over the 1850-2014 period and by the shared socioeconomic pathway SSP5-8.5 scenario (Eyring et al. 2016) for the climate change over 2015-2100. Owing to their design, differences between individual realizations are due solely to internally generated climate variability (Wallace et al. 2014; Deser et al. 2014).

Daily and monthly near-surface $(10 \mathrm{~m})$ wind speeds in the historical and climate change simulations are employed. The simulated extreme index U90 is created using 1961-1990 as the base period to be consistent with extreme temperature and precipitation indices as defined for these climate simulations (e.g., Yu et al. 2020, 2021). Nevertheless, the projected U90 trend is nearly identical if we use 1981-2010 as the base period. The modelled mean and extreme winds in the historical simulation over 1980-2014 are compared to the corresponding ERA5 results to evaluate the model performance. The projected wind trends over the next half-century are calculated using the climate change simulation over 2021-2070. In addition, the monthly surface air temperature (SAT) and sea-level pressure (SLP) in the climate simulations are employed. The modelled variables we considered are interpolated to $2.5^{\circ} \times 2.5^{\circ}$ grids using a bilinear interpolation.

\subsection{Analysis methods}

All analyses are based on DJF means of variables considered. The secular trend for the time series of interest is computed using the conventional regression method. The high-order variation components of temperature and wind changes are calculated using normalized orthogonal polynomial approximations (e.g., Hildebrand 1956). The multi-member ensemble mean $(\mathrm{EnM})$ quantity is obtained by averaging the statistics of the 50 members. Following Deser et al. (2014), we partition the projected trend $\left(X_{\text {Total }}\right)$ into externally anthropogenic forced $\left(X_{\text {Forced }}\right)$ and internal climate variability generated $\left(X_{\text {Internal }}\right)$ components:

$$
X_{\text {Total }}(i)=X_{\text {Forced }}(i)+X_{\text {Internal }}(i)=X_{\text {EnM }}+X_{\text {Internal }}(i),
$$

where $i$ refers to an individual ensemble member and $i=1, \ldots, 50 . X_{\text {Forced }}$ is estimated by averaging the projected trends over the 50 members (i.e., the EnM trend $X_{\mathrm{EnM}}$ ), whereas $X_{\text {Internal }}$ is obtained by subtracting $X_{\text {Forced }}$ from $X_{\text {Total }}$.

The signal-to-noise ratio (SNR) of the projected wind trend is calculated as a ratio of the EnM wind trend to the standard deviation of the 50 trends, which compares the externally forced trend to the internal climate variability related trend. In addition, a dynamical adjustment method is utilized to confirm the influence of large-scale circulation-induced 
variability on wind projections. Briefly, we characterize dominant modes of the inter-member variability of large-scale circulations by performing an empirical orthogonal function (EOF) analysis of the 50 SLP trends over 2021-2070. The three leading SLP predictors are determined for wind trends using the method of partial least squares. The dynamically adjusted trend is then obtained by removing the influence of these three orthogonal SLP predictor patterns in the wind trend.

The relative agreement of wind patterns for individual members with the ERA5 reanalysis or EnM result is assessed by examining second-order pattern difference statistics and is illustrated in a BLT diagram (Boer and Lambert 2001). A BLT diagram is a modified Taylor diagram, which displays the pattern correlation, the ratio of model to ERA5 or EnM variances, and the relative mean square difference between each ensemble member and ERA5 or EnM quantities. In addition, as in Deser et al. (2012) and Chen and Yu (2020), EnM values that are significantly different from zero at the $95 \%$ confidence level relative to the spread of the 50 individual results are assessed by the criterion:

$$
|E n M| \geq \frac{2 \times \mathrm{STD}}{\sqrt{N-1}},
$$

where $|\mathrm{EnM}|$ is the absolute value of the EnM, STD the standard deviation of anomalies relative to the EnM, and $N=50$.

The geostrophic flow is a theoretical wind resulting from the balance between the pressure gradient force and the Coriolis force, which typically occurs above boundary friction layer in mid-latitudes. Using the ideal gas law, horizontal components of the geostrophic wind $\left(u_{\mathrm{g}}, v_{\mathrm{g}}\right)$ can be approximated as:

$$
\begin{gathered}
u_{\mathrm{g}}=-\frac{R}{f} \frac{\partial T}{\partial y}, \\
v_{\mathrm{g}}=\frac{R}{f} \frac{\partial T}{\partial x},
\end{gathered}
$$

where $R=287 \mathrm{Jdeg}^{-1} \mathrm{~kg}^{-1}$ is the gas constant for dry air, $f=2 \Omega \sin \varphi$ the Coriolis parameter varying with latitude $\varphi, \Omega=7.292 \times 10^{-5} \mathrm{rad} \mathrm{s}^{-1}$ the angular velocity of rotation for the earth, and $T$ the air temperature. We calculate the idealized geostrophic wind change using SAT projections to assess the driving force of air temperature on wind changes.

\section{Surface wind}

\subsection{Climatological mean}

Figure 1 (left panels) displays the DJF climatological means of surface wind speed over the 1980-2014 period for the EnM of CanESM5 historical simulations and the ERA5 reanalysis. Strong wind speeds, with values exceeding $4 \mathrm{~ms}^{-1}$, mainly appear over the central USA, northern Canada, Greenland, Sahara, Middle East, Central Asia, the Tibetan Plateau, northern Russia, Argentina, South Africa, and western-central Australia. Broadly similar patterns are seen in the EnM and ERA5, with a pattern correlation of 0.76 over land within the domain $\left(60^{\circ} \mathrm{S}-80^{\circ} \mathrm{N}\right)$ of interest. However, the wind pattern is smoother in the EnM than ERA5, likely due to the multi-member 


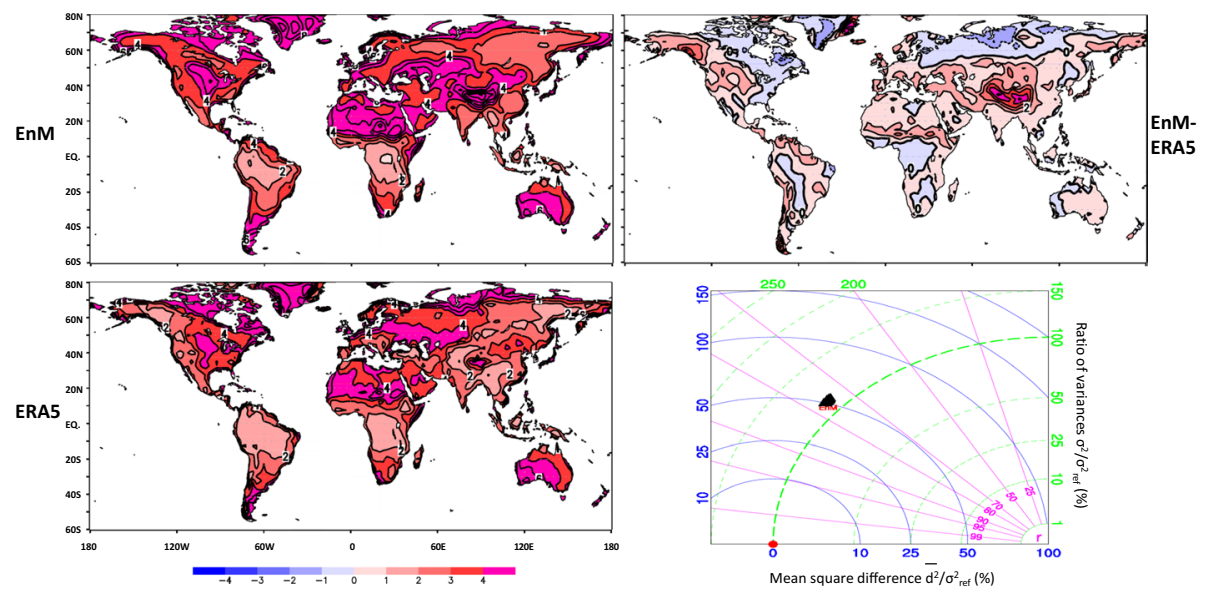

Fig. 1 DJF climatological means of surface wind speed over the 1980-2014 period for the EnM of CanESM5 simulations (top left), ERA5 reanalysis (bottom left), and difference between them (EnM-ERA5, top right). Contour interval is $1.0 \mathrm{~ms}^{-1}$. BLT diagram (bottom right) illustrating the pattern correlation (magenta), the ratio of model to reanalysis variance (green), and the relative mean square difference (blue) between each simulation and reanalysis results of DJF climatological mean winds over 1980-2014, in unit percentage. The EnM result is also shown

average. The difference between them (EnM-ERA5, Fig. 1, top right) is mostly apparent in magnitude of wind, especially in high-topography regions such as the Tibetan Plateau, Rocky Mountains, Sahel, and Atacama Desert. Similar model biases are also found in sea-level pressure (Swart et al. 2019). The wind pattern seen in EnM is robust for all ensemble members. Figure 1 (bottom right) also shows the relative agreement of the climatological mean winds for individual members relative to the ERA5 result using a BLT diagram. The pattern correlations are $0.75-0.77$ for the 50 members. Meanwhile, all members simulate slightly higher spatial variances compared to ERA5, with the ratio of model to ERA5 variances of about $110 \%$. The distinction between individual members is hence hardly discernible in the diagram. The mean square difference between model and reanalysis based patterns is about $50 \%$, as distributed in the wind speed difference described above. Overall, the ERA5-based wind speed pattern is reasonably well simulated by CanESM5.

The discrepancy between the EnM and ERA5 may result from differences in the configuration and physics of the CanESM5 and ERA5 reanalysis models. In particular, the difference can be partially attributed to differences in considering the uneven underlay surface, the land-surface roughness and elevation representation (e.g., Ramon et al. 2019; Goyal et al. 2021). The model resolution has a significant influence on the surface roughness and elevation representation; in particular, coarser resolution models tend to simulate stronger wind speeds over high-elevated mountain ranges (Ramon et al. 2019). This applies to the difference between CanESM5 and ERA5. CanESM5 has a horizontal resolution of approximately $2.8^{\circ}$ in the atmosphere (about $222 \mathrm{~km}$ at $45^{\circ}$ of latitude), whereas ERA5 has a high resolution of $31 \mathrm{~km}$. Stronger winds are apparent over high mountain regions in CanESM5 than ERA5 (Fig. 1, top right). Nevertheless, the model bias will be partly removed when using individual integrations to calculate climate change trends (e.g., Yu et al. 2020, 2021). 


\subsection{Projected trend}

Figure 2 (top left) shows the ensemble mean of normalized surface wind speed trends over 2021-2070. Here we normalize the wind trend at each grid by its climatological mean over 1951-2000 to make global trends more comparable to each other. In terms of the intermember agreement according to Eq. (2), the trend is projected to mostly decrease in the $\mathrm{NH}$ mid-low latitudes and $\mathrm{SH}$ mid-latitudes and increase in the $\mathrm{NH}$ high latitudes and $\mathrm{SH}$ tropical and subtropical regions, with considerable regional variations. The wind trends are also field significant at the 5\% level over the global land, as discussed in the Supplementary and Table S1. The broad wind reductions over northern mid-latitudes and increases across tropical and southern subtropical regions feature an interhemispheric asymmetry, as illustrated by a quartic fit on the zonal average (red curve in top right of Fig. 2). The interhemispheric asymmetry of wind projections generally resembles the result of Karnauskas et al. (2018), obtained from an ensemble of 10 CMIP5 climate change simulations in wind power. However, differences in regional projections, especially changes in tropical regions, are evident between them (cf. top panels in Fig. 2 with Fig. 3 in Karnauskas et al. 2018). Karnauskas et al. (2018) explore annual mean wind power changes, where winds are interpolated to hub height and projected changes in air density are considered, whereas we analyze DJF mean surface wind speeds. The different factors considered in the two studies

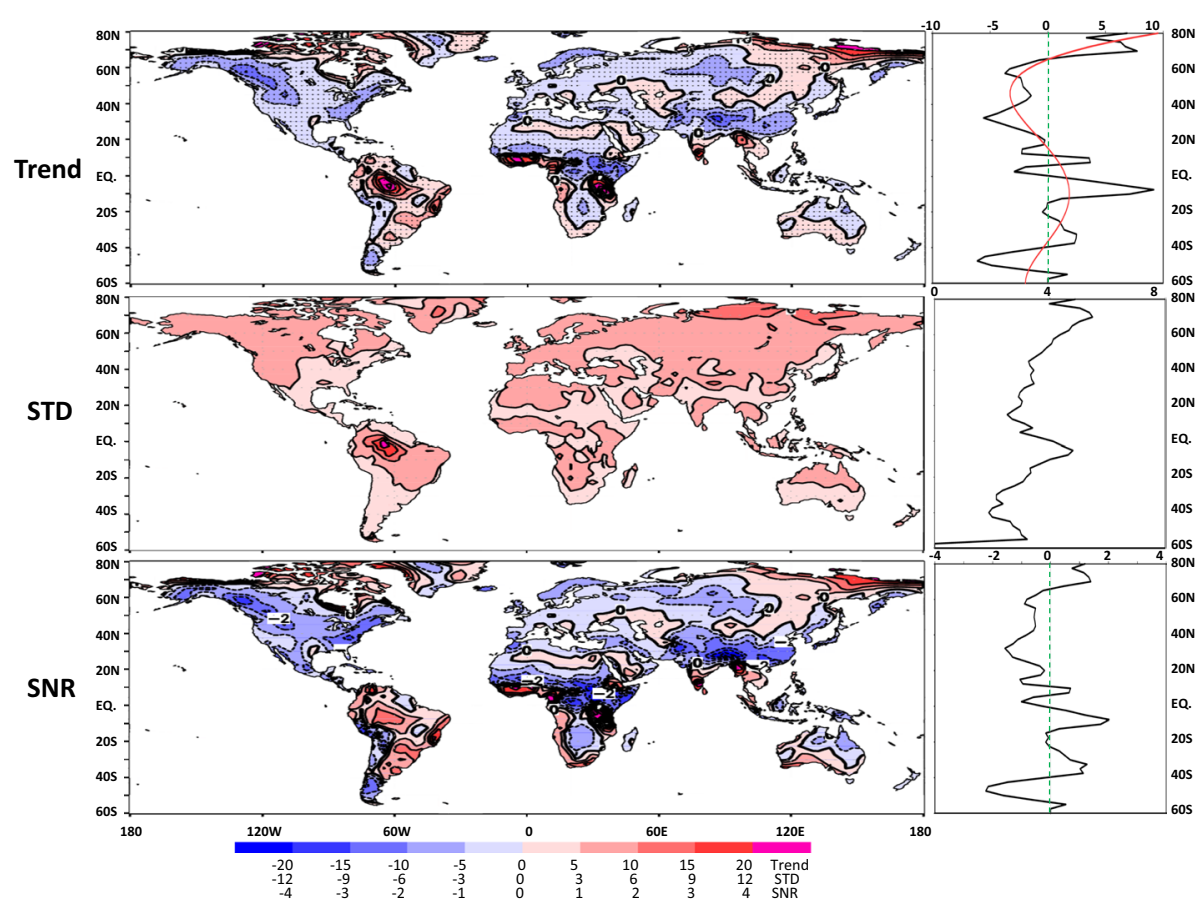

Fig. 2 Normalized wind speed trend over 2021-2070 (top left, interval 5.0\%/50 years) for the ensemble mean. Stippling regions indicate trends significant at the $95 \%$ confidence level. Standard deviation (middle left, interval 3.0\%/50 years) and signal-to-noise ratio (bottom left, interval 1.0) of the normalized wind speed trends among the 50 ensemble members. Zonal averages of the trend (superimposed by a quartic fit in red), standard deviation, and signal-to-noise ratio are shown from the top right to the bottom right 

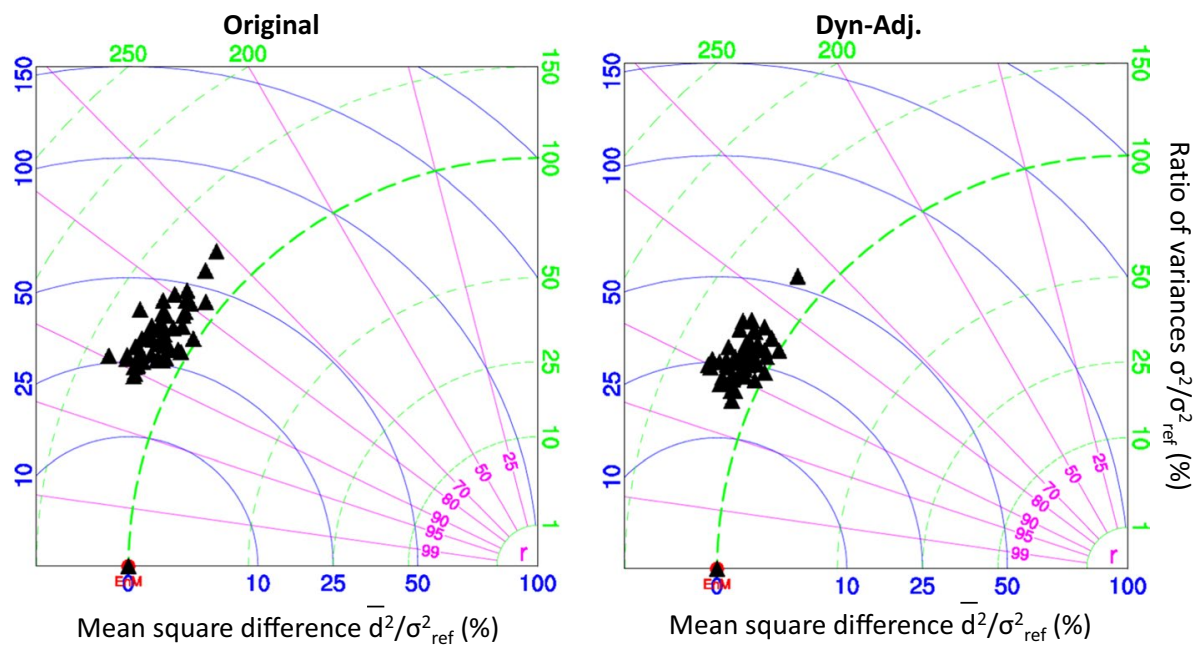

Fig. 3 (left) BLT diagram illustrating the pattern correlation, the ratio of model to EnM variance, and the relative mean square difference between each simulation and EnM values of normalized wind trend over the 2021-2070 period, in unit percentage. (right) As in left, but for the corresponding dynamically adjusted results

may cause the result difference. In addition, the discrepancy may also result from differences in climate models employed, as well as the ensemble number and external forcing used.

The spread of the normalized wind trends in CanESM5 simulations can be quantified by the standard deviation (STD) of trends across the 50 ensemble members. The inter-member variability (Fig. 2, middle left) reveals a broadly uniform structure, with values about 3-6\%/50 years, especially over northern mid-latitudes. Nevertheless, relatively high variances exceeding 6\%/50 years are apparent over western Brazil and northern Russia, which contribute to high zonal averages of variation in those latitudes (Fig. 2, middle right). The signal-to-noise ratio pattern (Fig. 2, bottom panel) bears resemblance to the EnM wind trend, indicating that the surface wind response to external forcing tends to be more detectable over those regions with significant wind changes as described above (Fig. 2, top left).

Figure 3 (left) further compares the wind trend patterns in individual members to the EnM. The pattern correlations over the global land range from 0.71 to 0.91 , indicating a broad similarity of the wind projections across the 50 members. However, the ensemble members have slightly higher spatial variances compared to the EnM, with the ratio of variances ranging from 105 to $135 \%$. In addition, the mean square difference between each simulation and the EnM is about $25-50 \%$ for most members. These suggest diversities, in terms of magnitude and spatial structure of the projected trend, also appear across the ensemble members.

\subsection{Internally generated and dynamically adjusted trends}

The projected wind speed trend $\left(X_{\text {Total }}\right)$ is further partitioned into externally forced $\left(X_{\text {Forced }}\right)$ and internal climate variability generated $\left(X_{\text {Internal }}\right)$ components, as indicated in Eq. (1). $X_{\text {Forced }}$ is estimated by the EnM trend discussed above. $X_{\text {Internal }}$ reveals large diversities 
among the 50 members. Member 02 (M02) has the highest pattern correlation of $X_{\text {Total }}$ with the EnM ( $r=0.91)$, while member 28 (M28) has the lowest correlation $(r=0.71)$. For the total trend (Fig. 4, top panels), the two cases exhibit broadly similar structure, with a pattern correlation of 0.69 . However, notable differences, especially in magnitude of trend, are also seen between them. Opposite trends are even apparent in northern parts of South America and central parts of North America. Wind reductions dominate northern mid-latitude regions in both M02 and M28, although there are weak increases in central parts of North America and Asian mid-latitudes in M02. By contrast, increases (decreases) of wind dominate southern tropical and subtropical regions in M02 (M28). Hence, a roughly interhemispheric asymmetry of wind projections can be seen in M02 but not in M28 (Fig. 4, top right). The difference between M02 and M28 is also evident in $X_{\text {Internal }}$ (Fig. 4, bottom panels). The internal trend reveals large-scale spatial coherence rather than small-scale noise structure, similar to the feature seen in temperature projections (e.g., Deser et al. 2014; Yu et al. 2021). However, the pattern correlation of $X_{\text {Internal }}$ between M02 and M28 is low $(r=0.11)$, owing to substantial regional variations of the trend. In addition, the magnitude of $X_{\text {Internal }}$ is comparable to $X_{\text {Forced }}$, apparent in the spatial pattern and zonal average of trend (cf. bottom panels in Fig. 4 with top panels in Fig. 2).

The interhemispheric asymmetry of wind projections can be seen in about three-fourths of the 50 members (not shown). However, differences in total and internal trends are also found between individual members, especially over northern parts of South America and northern Russia, as would be expected from the inter-member variability of trend (Fig. 2, middle panels). Therefore, both the externally forced and internally generated components contribute noticeably to the projected wind trend.

The large-scale atmospheric circulation influences surface wind speed (e.g., Pryor et al. 2006; Vautard et al. 2010; Wu et al. 2018; Zeng et al. 2019). The circulation-induced variability also plays an important role in climate change projections (e.g., Deser et al. 2012, 2014; Holmes et al. 2016; Yu et al. 2021). To assess the impact of large-scale circulation-induced variability on the wind speed trend, we perform an EOF analysis on the SLP

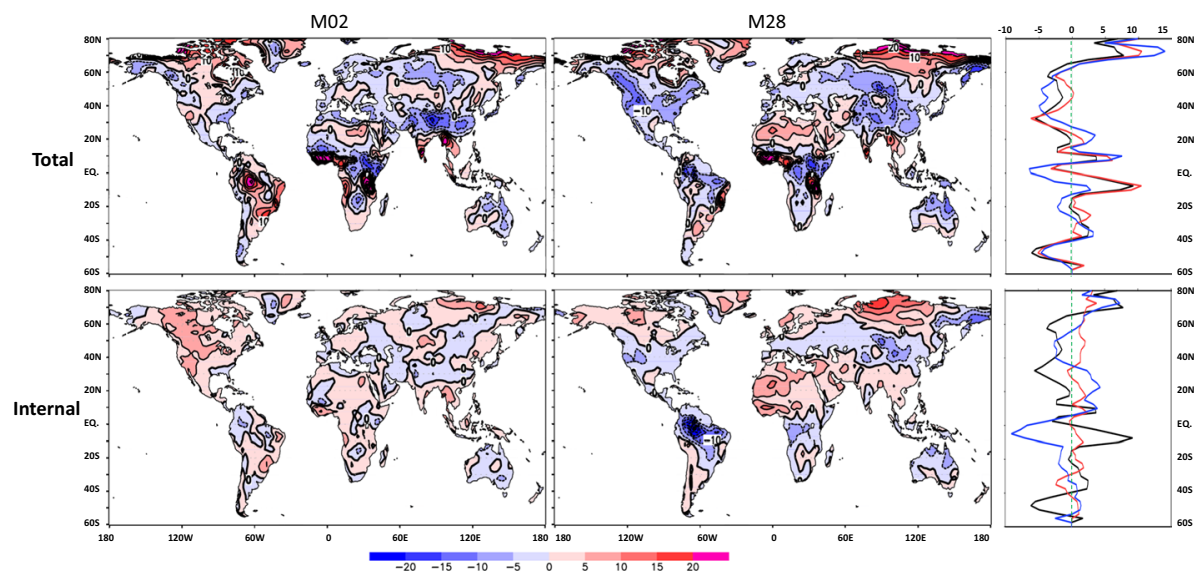

Fig. 4 Total (top row) and internal components (bottom row) of the normalized wind speed trend over 2021-2070 for member 02 (left column) and member 28 (middle column). Contour interval is 5.0\%/50 years. (top right) Zonal averages of the total trend for the EnM (black), M02 (red), and M28 (blue). (bottom right) Zonal averages of the total trend for the EnM (black) and of the internal trend for M02 (red) and M28 (blue) 
trends over $2021-2070$ across the 50 members, within the $60^{\circ} \mathrm{S}-80^{\circ} \mathrm{N}$ domain involving land and oceans. The three leading EOF modes account for $56.8 \%(30.3 \%, 16.4 \%$, and $10.1 \%$ for individuals, respectively) of the inter-member SLP trend variance and are well separated from subsequent modes according to the criterion of North et al. (1982). These leading modes are dominated by centers of action over the NH (Supplementary Fig. S2). Specifically, EOF1 exhibits an Arctic Oscillation (AO, Thompson and Wallace 1998)-like pattern, with opposite SLP anomalies over the Arctic region and northern mid-latitudes. EOF2 bears resemblance to the East Atlantic pattern (EA, Wallace and Gutzler 1981), with a dominant action center over western Eurasia. EOF3 features a Western Pacific (WP, Wallace and Gutzler 1981)-like pattern, with a dominant action center over the Kamchatka Peninsula. In addition, similar results can be obtained from an EOF analysis over the northern extratropical domain $\left(20^{\circ}-80^{\circ} \mathrm{N}\right)$, indicating SLP variations in boreal winter are dominated by large-scale circulation anomalies in the northern extratropics.

The three orthogonal SLP trend predictors are subsequently determined for wind trends and removed to obtain the dynamically adjusted wind trend for individual simulations. By partially removing the circulation-induced component of internal variability, the dynamically adjusted trends in M02 and M28 (Fig. 5) are more comparable to the EnM trend, with the pattern correlation between M02 (M28) and EnM increasing slightly from 0.91 (0.71) for the total trend to $0.93(0.75)$ for the adjusted trend. The similarity between the adjusted M02 and M28 trends is also higher than that of the corresponding total trends (cf. Figure 5 with top panels in Fig. 4), with the correlation between them increasing from 0.69 for the total trend to 0.77 for the adjusted trend. In addition, the dynamically adjusted wind trends for the 50 ensemble members are compared to the EnM (Fig. 3, right). The pattern correlations between each member and EnM range from 0.75 to 0.93 , with a mean of 0.88 that is higher than the mean of the total trend (0.83). The mean square difference between each member and EnM for the adjusted trend is also lower than that of the total trend. The above results confirm that the spread in wind projections is partially due to the large-scale circulation-induced internal variability.

\subsection{The influence of air temperature on wind trend}

Motion in the atmosphere is governed by the pressure gradient, Coriolis, and friction forces, as well as the gravitational force for vertical motion. One driving force of surface wind is air temperature because SAT changes affect surface pressure gradients and hence wind changes (e.g., Solomon et al. 2007). This can be illustrated by

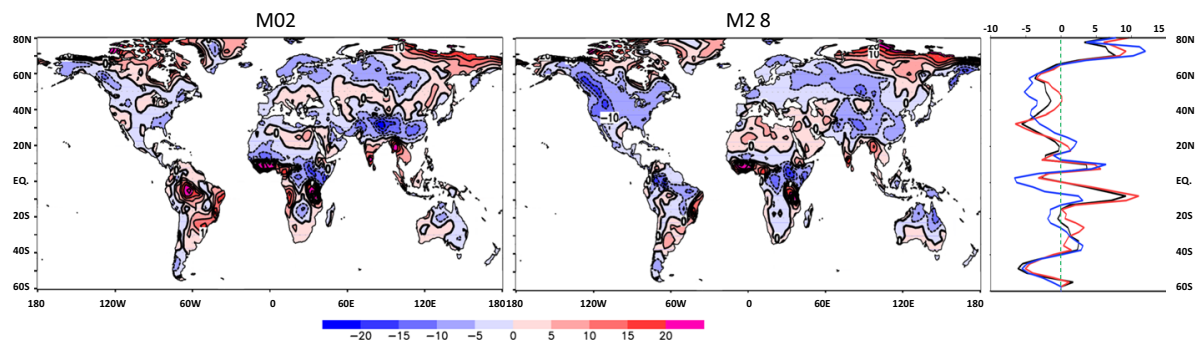

Fig. 5 Dynamically adjusted components of the normalized wind speed trend for member 02 (left) and member 28 (middle). Contour interval is 5.0\%/50 years. (right) Zonal averages of the total trend for the EnM (black) and of the adjusted trend for M02 (red) and M28 (blue) 
the geostrophic wind approximation, as indicated in Eqs. (3, 4). The geostrophic wind is a good approximation that typically appears above boundary layer in mid-latitudes. However, the geostrophic balance does not apply near the surface where winds are influenced by the friction resistance. Additionally, the geostrophic wind does not occur in tropical latitudes where the Coriolis force is weak. Nevertheless, Eqs. $(3,4)$ provide a straightforward way to assess the driving force of air temperature on wind.

Figure 6 displays the normalized geostrophic wind speed trend and its zonal and meridional components, calculated from the ensemble mean SAT trend over 2021-2070. We normalize the wind trend and its horizontal components by the climatological mean geostrophic wind speed over 1951-2000 at each grid. The wind speed trend is dominated by its zonal component, indicating that the contribution from the meridional temperature gradient is generally higher than the zonal temperature gradient, especially in northern mid-latitudes. In addition, the pattern of geostrophic wind trend bears resemblance to the CanESM5 simulated wind trend pattern, with considerable spatial variations (cf. top left in Fig. 6 with top left in Fig. 2). An interhemispheric asymmetry, featured by broad decreases of geostrophic wind in most of northern midlatitudes and increases across most of tropical and southern subtropical regions, is also evident (Fig. 6, top left and zonal averages in right panels). The similarity in the trends

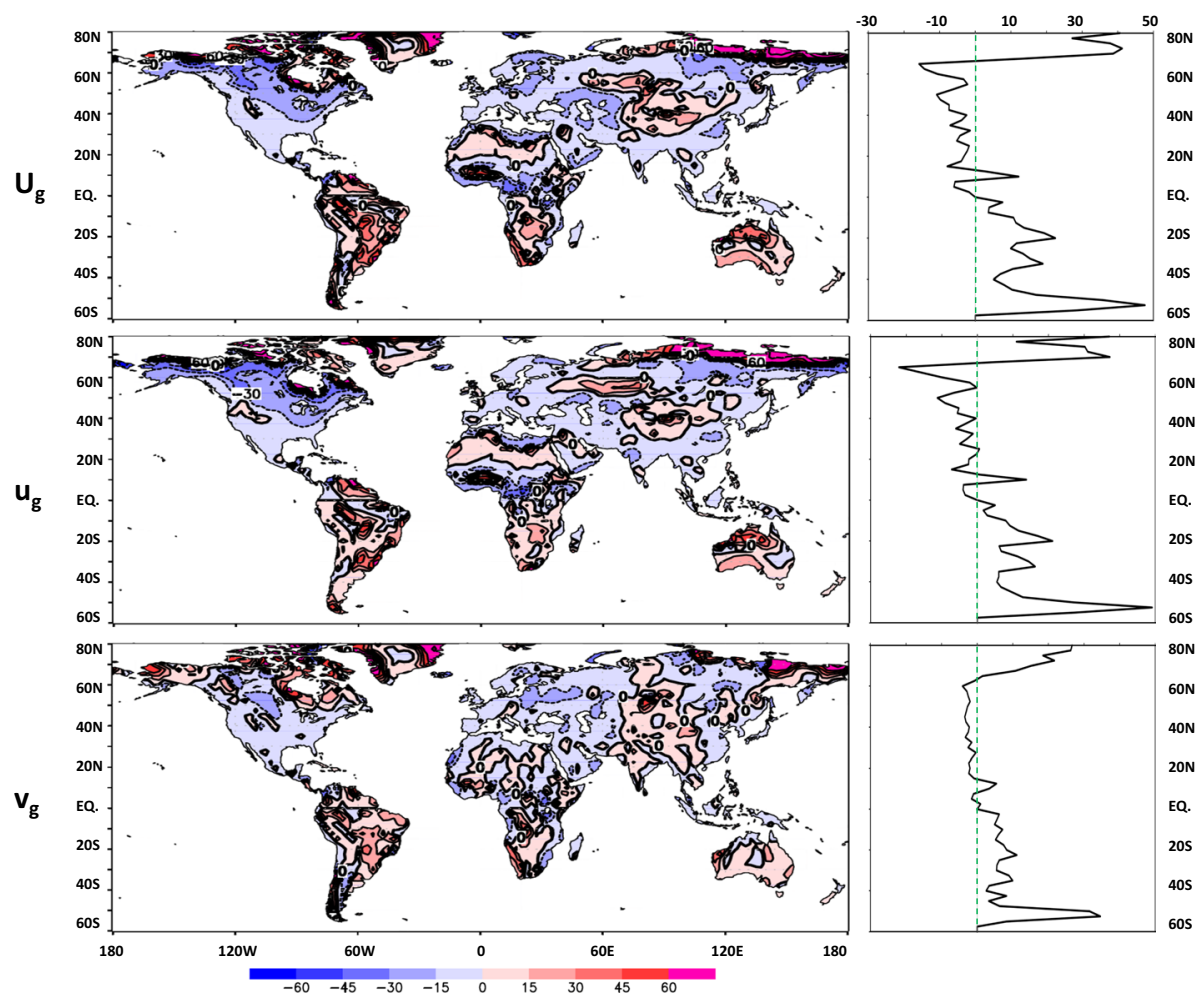

Fig. 6 Normalized geostrophic wind speed trend (top left) and its zonal (middle left) and meridional (bottom left) components, calculated from the ensemble mean SAT trend over 2021-2070. Contour interval is $5.0 \% / 50$ years. Zonal averages of the normalized geostrophic wind speed trend and its zonal and meridional components are shown from the top right to the bottom right 
of simulated and geostrophic winds indicates the important driving force of air temperature on projected wind changes.

The interhemispheric asymmetry of wind changes can be further schematically illustrated in Fig. 7. The zonal averages of SAT changes in DJF for the two periods over 2001-2050 and 2051-2100 relative to 1951-2000 both reveal a signature of poleward amplification (Fig. 7, left), which can be well represented by fourth order polynomial fits. The geostrophic wind change (Fig. 7, right) is then calculated from the simplified temperature change. The interhemispheric asymmetry of wind changes can be schematically illustrated in both periods, indicating the robustness of the asymmetry feature over time.

\section{Surface extreme wind}

\subsection{Climatological mean}

Based on the definition, the climatological mean extreme wind index U90 over the 1980-2014 period is close to 10\% for the ERA5 reanalysis (not shown). The corresponding EnM of climate simulations over the same period also shows values around $10 \%$ (Fig. 8, left). The climatological mean is slightly different from $10 \%$, which is mainly due to climate differences between the base period 1961-1990 employed to define the simulated U90 and the period 1980-2014 considered here and to daily wind variability. We have also compared the relative agreement of the DJF mean U90 patterns for individual members to

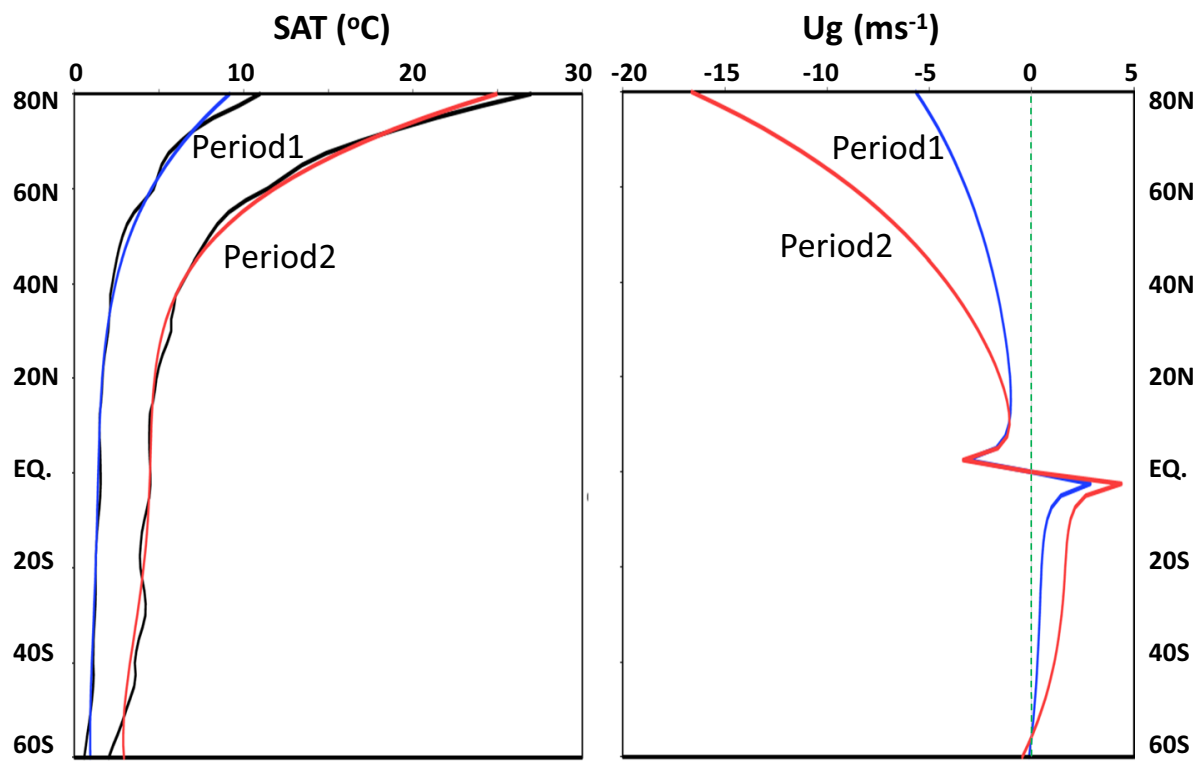

Fig.7 Zonal averages of DJF mean SAT changes (left, black curves in unit ${ }^{\circ} \mathrm{C}$ ) for the period 1 of $2001-$ 2050 relative to 1951-2000 and period 2 of 2051-2100 relative to 1951-2000, together with a quartic fit to each zonal average (blue and red curves for periods 1 and 2, respectively). Corresponding geostrophic wind speed changes (right, unit $\mathrm{ms}^{-1}$ ) for the two periods, calculated from the simplified quartic fits of SAT changes 


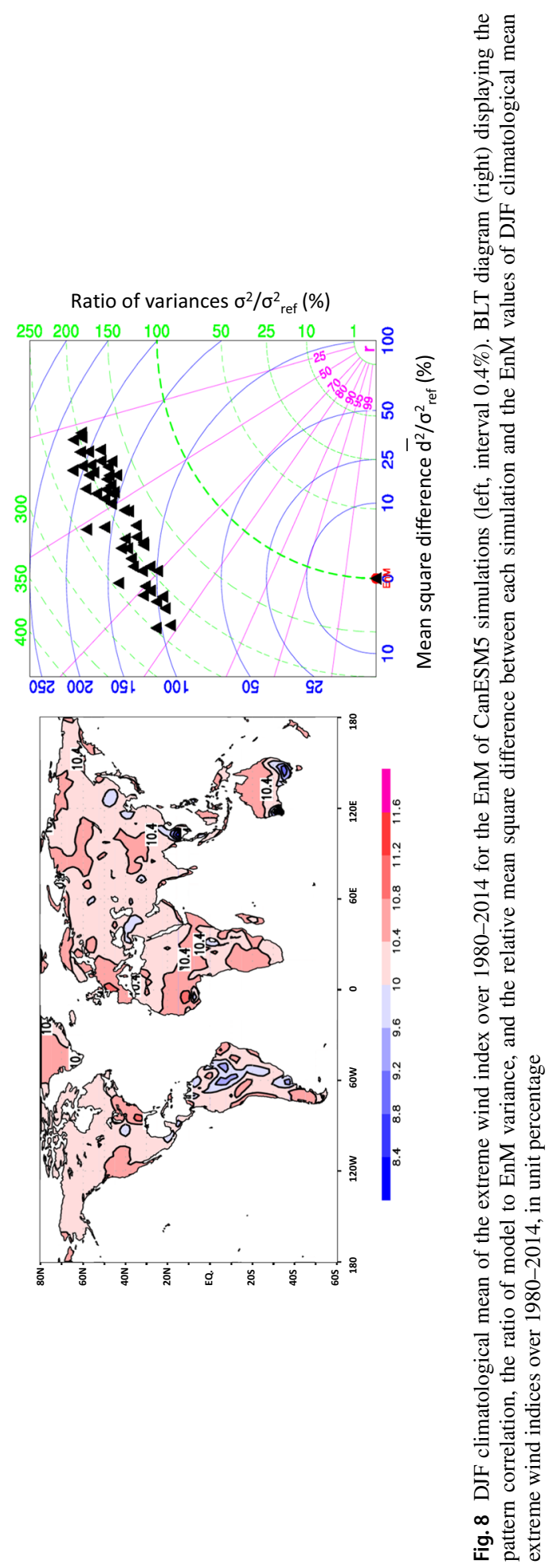


the EnM. Considerable differences are apparent in spatial correlation and variance of U90. The pattern correlations reveal a wide range from 0.28 to 0.78 across the 50 members, and the ratios of each member to EnM variance range from 175 to $245 \%$ (Fig. 8, right). This indicates large uncertainties in simulating spatial pattern and magnitude of the extreme wind, and suggests the internal climate variability tends to influence extreme wind U90 more than mean wind $U$ (cf. right panel in Fig. 8 with bottom right panel in Fig. 1).

\subsection{Projected trend}

Figure 9 (top left) displays the ensemble mean trend of DJF mean U90 over 2021-2070. The spatial distribution of the extreme wind trend resembles that of the normalized seasonal mean wind trend (cf. top left in Fig. 9 with top left in Fig. 2), and is also field significant at the 5\% level (Supplementary Table S1). However, reductions of U90 tend to be more consistent over northern mid-latitudes than the corresponding reduction of $U$. This is also evident in relatively weak variations of the zonal average U90 trend across northern mid-latitudes (Fig. 9, top right). Consequently an interhemispheric asymmetry of U90 changes is also found (Fig. 9, top right). In addition, the inter-member variability of the U90 trend is about 1.0-2.5\%/50 years over most regions, except high variances exceeding 3.0\%/50 years over northern parts of South America, south of West Africa, and Angola (Fig. 9, middle panels). The SNR pattern (Fig. 9, bottom panel) also resembles the EnM U90 trend.

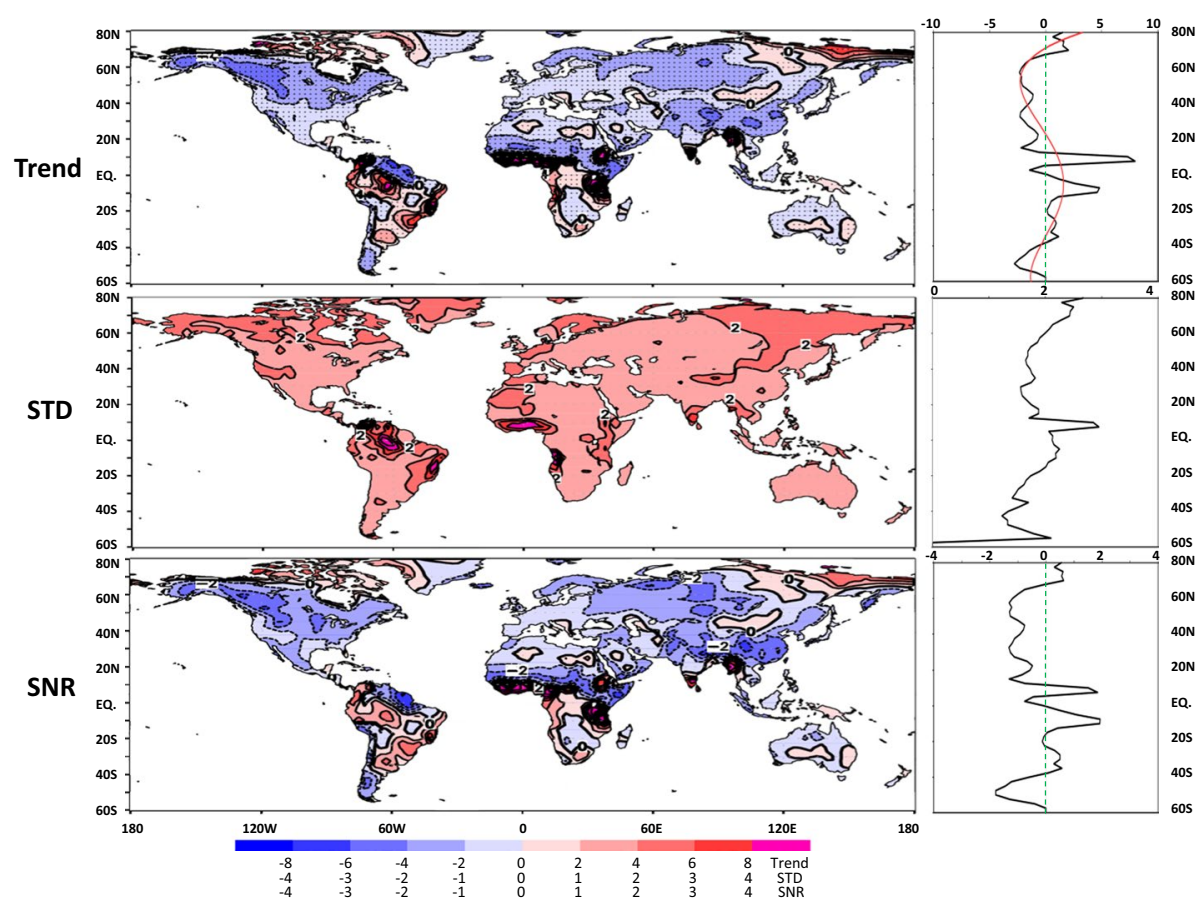

Fig. 9 As in Fig. 2, but for the extreme wind trend. Contour intervals are 2.0\%/50 years for the trend, and $1.0 \% / 50$ years for the standard deviation 
The similarity of the U90 trends across the 50 members is illustrated by high pattern correlations between individual members and EnM (0.86-0.93, left panel in Fig. 10). Meanwhile, individual simulations exhibit slightly higher spatial variances than the EnM variance, with the variance ratio below $125 \%$. The mean square difference between each member and the EnM is below 30\%. The good correspondence among the 50 members indicates relatively stable U90 projections. Hence, the interhemispheric asymmetry of extreme wind changes can be expected in the next half-century, although large uncertainties are seen in the climatological mean U90 in individual simulations.

\subsection{Internally generated and dynamically adjusted trends}

The extreme wind trend is also decomposed into externally anthropogenic forced and internal climate variability generated components. Figure 11 displays the total and internally generated U90 trends for the two members that have the highest ( $r=0.93$; member 37, M37) and lowest ( $r=0.86$; member 01, M01) pattern correlations with the EnM. The two members exhibit broadly similar structure of total trend compared to the EnM, as well as the interhemispheric asymmetry feature (Fig. 11, top panels). The pattern correlation of total trend between M37 and M01 is 0.80 . The discrepancy between them is mainly in magnitude of the trend, except opposite trends over northeastern China and patches of small areas. M01 depicts increases of U90 over northeastern China, which is opposite to those in M37 and EnM. The difference is also evident in the internally generated trend (Fig. 11, bottom panels), which shows large-scale spatial coherence over land. In addition, the internally generated trend is comparable to the forced trend, especially over action centers of the internal trend in northern mid-high latitudes, and hence contributes to the total trend.

Given the relationship between the large-scale circulation variability and synoptic-scale atmospheric variations (e.g., Wallace and Gutzler 1981; Vose et al. 2014; Yu et al. 2019), we also remove influences of the three leading SLP trend predictors described in last section, to obtain a dynamically adjusted U90 trend. By partially reducing the contribution of
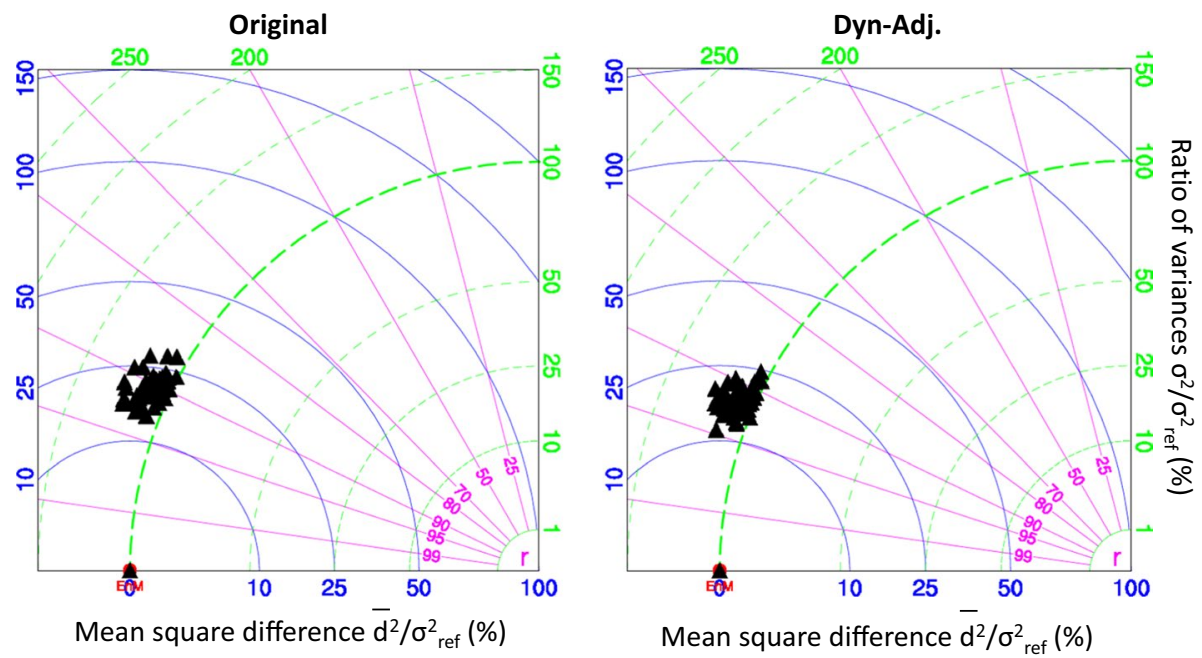

Fig. 10 As in Fig. 3, but for the extreme wind trend 


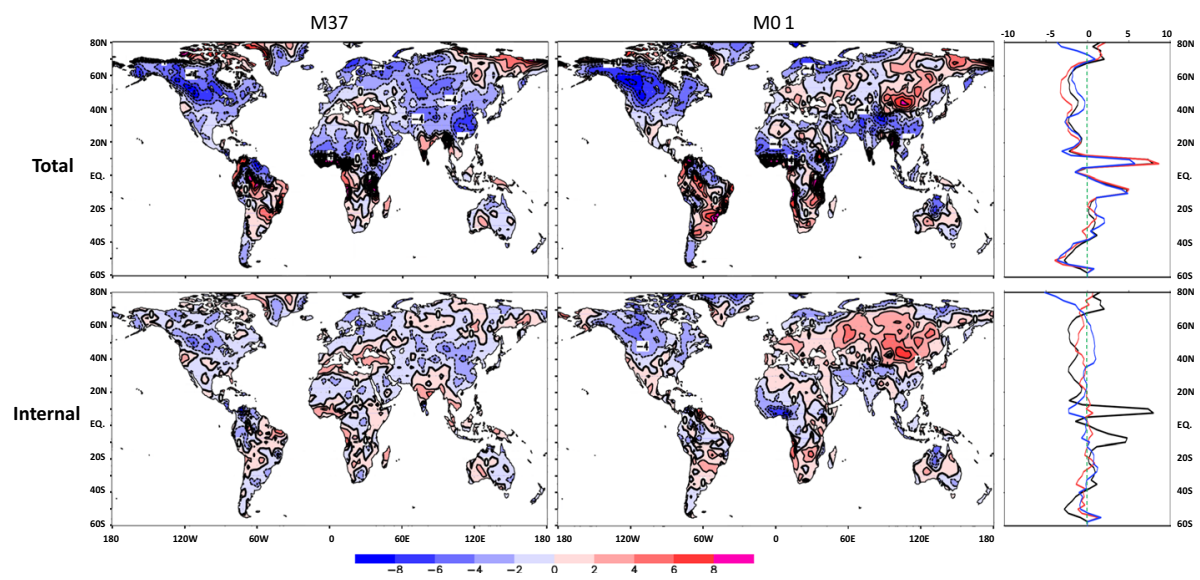

Fig. 11 As in Fig .4, but for the extreme wind trends of member 37 (left column) and member 01 (middle column) with contour interval $2.0 \% / 50$ years

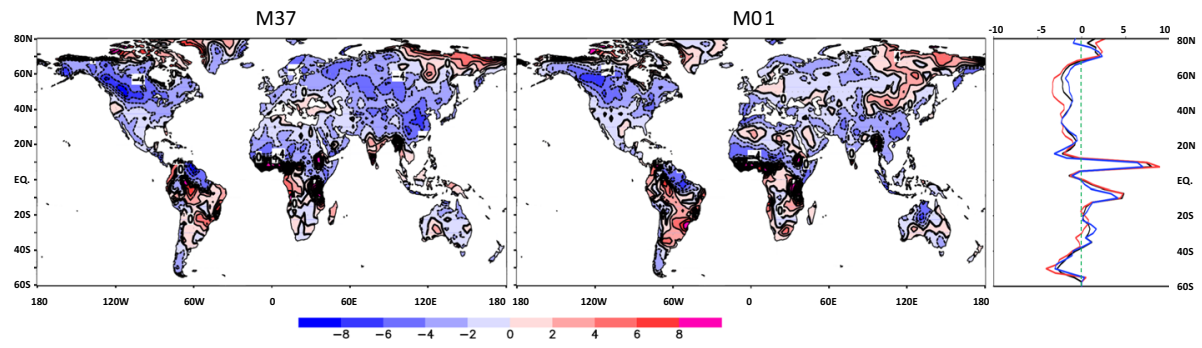

Fig. 12 As in Fig. 5, but for the extreme wind trends of member 37 (left) and member 01 (middle) with contour interval $2.0 \% / 50$ years

the large-scale circulation-induced component, increases of U90 over northeastern China in M01 are weaker in the adjusted trend than total trend (Fig. 12). Meanwhile, the pattern correlation of the adjusted trend between M01 and M37 is 0.85, slightly higher than that of the total trend (0.80). In addition, the pattern correlation between M01 and EnM increases from 0.86 for the total trend to 0.91 for the adjusted trend, and increases slightly from 0.93 to 0.94 between M37 and EnM. The spatial correlation and variance for individual members to the EnM for the adjusted U90 trend have also been compared (Fig. 10, right panel). The pattern correlations range from 0.88 to 0.95 , with a mean of 0.93 that is slightly higher than the mean of total trend (0.91). In addition, the ratio of individual member to EnM variances and the mean square difference between each member and EnM for the adjusted trend are slightly lower than the counterparts of total trend. Overall, the spread in U90 projections decreases by partially removing the large-scale atmospheric circulation variability. 


\section{Summary and discussion}

Based on a 50-member SMILE of climate simulations generated by CanESM5, we analyze the ensemble mean and spread of future projections of global surface mean and extreme winds in boreal winter. The simulations are forced by historical anthropogenic and natural forcings over 1850-2014 and the SSP5-8.5 high-emissions scenario over 2015-2100. To evaluate the performance of CanESM5, modelled surface winds in the historical simulation over 1980-2014 are compared to the corresponding ERA5 result. The projected wind trends over the next half-century are subsequently analyzed using the climate change simulation over 2021-2070. We examine the externally anthropogenic forced and internal climate variability generated components of projected surface mean and extreme wind trends, and explore the influence of large-scale atmospheric circulation-induced variability on these trends. The main findings can be summarized as follows.

(1) CanESM5 can reasonably well simulate the ERA5 based surface wind speed pattern, with differences mainly over high-topography regions. The discrepancy may be partially attributed to different grid resolutions of the climate and reanalysis models, which influence the land-surface roughness and elevation representation.

(2) Surface wind speed over the next half-century is projected to mostly decrease in northern mid-low latitudes and southern mid-latitudes and increase in northern high latitudes and southern tropical and subtropical regions, with considerable regional variations. The broad reduction over northern mid-latitude regions and increase across tropical and southern subtropical regions feature an interhemispheric asymmetry. The driving force of air temperature plays an important role in the wind projection, as seen in the geostrophic wind approximation. The interhemispheric asymmetry of wind projection is apparent in most ensemble members, with remarkable differences over northern parts of South America and northern Russia.

(3) The projected extreme wind change resembles the mean surface wind change. However, reductions of the extreme wind tend to be more consistent over northern mid-latitudes. The interhemispheric asymmetry of future extreme wind changes is found in all ensemble members, although large uncertainties are evident in the climatological mean of extreme wind in individual simulations.

(4) The projected surface mean and extreme wind changes are attributed to changes in both externally anthropogenic forced and internal climate variability generated wind components. The internally generated wind trend reveals large-scale spatial coherence, similar to the feature previously found in temperature projections. The spread in surface wind projections is partially due to large-scale atmospheric circulation variability.

Extreme wind projections reported here are based on an index defined with the percentage of time when daily wind speed is above its 90th percentile. Similar results can be obtained using an index defined with daily maximum wind speed. Nevertheless, the robustness of surface mean and extreme wind projections remains to be explored in other CMIP6 climate simulations. In addition, the dynamically adjusted approach we utilized to consider large-scale circulation-induced variability on wind projections is similar to adjustments by means of partial least squares regressions applied in temperature and precipitation studies (e.g., Wallace et al. 2014; Deser et al. 2014; Hu et al. 2019), and differs from the adjusted method based on constructed atmospheric circulation analogs (e.g., Deser et al. 2016; Gong et al. 2019). Regional-scale and synoptic-scale circulation variability can 
also influence wind variations, especially for extreme winds. How and to what extent various spatial and temporal scale climate variability impacts surface wind projections remain to be investigated.

Supplementary Information The online version contains supplementary material available at https://doi. org/10.1007/s10584-022-03313-2.

Acknowledgements We are indebted to colleagues at the CCCma in producing the climate simulations analyzed here. We thank Prof. K. Karnauskas and three anonymous reviewers for their constructive suggestions and comments, which helped to improve the study. Data used in this analysis are described in "Section 2".

Open Access This article is licensed under a Creative Commons Attribution 4.0 International License, which permits use, sharing, adaptation, distribution and reproduction in any medium or format, as long as you give appropriate credit to the original author(s) and the source, provide a link to the Creative Commons licence, and indicate if changes were made. The images or other third party material in this article are included in the article's Creative Commons licence, unless indicated otherwise in a credit line to the material. If material is not included in the article's Creative Commons licence and your intended use is not permitted by statutory regulation or exceeds the permitted use, you will need to obtain permission directly from the copyright holder. To view a copy of this licence, visit http://creativecommons.org/licenses/by/4.0/.

\section{References}

Bett PE, Thornton HE, Clark RT (2017) Using the twentieth century reanalysis to assess climate variability for the European wind industry. Theor Appl Climatol 127:61-80

Boer GJ, Lambert S (2001) Second-order space-time climate difference statistics. Clim Dyn 17:213-218

Chen S, Yu B (2020) Projection of winter NPO-following winter ENSO connection in a warming climate: uncertainty due to internal climate variability. Clim Change. https://doi.org/10.1007/ s10584-020-02778-3

Deng K, Azorin-Molina C, Minola L, Zhang G, Chen D (2021) Global near-surface wind speed changes over the last decades revealed by reanalyses and CMIP6 model simulations. J Clim 34:2219-2234

Deser C, Phillips AS, Bourdette V, Teng H (2012) Uncertainty in climate change projections: the role of internal variability. Clim Dyn 38:527-546. https://doi.org/10.1007/s00382-010-0977-x

Deser C, Phillips AS, Alexander MA, Smoliak BV (2014) Projecting North American climate over the next 50 years: uncertainty due to internal variability. J Clim 27:2271-2296. https://doi.org/10.1175/ JCLI-D-13-00451.1

Deser C, Terray L, Phillips AS (2016) Forced and internal components of winter air temperature trends over North America during the past 50 years: mechanisms and implications. J Clim 29:2237-2258

Eyring V et al (2016) Overview of the coupled model intercomparison project phase 6 (CMIP6) experimental design and organization. Geosci Model Dev. 9:1937-1958

Gong H, Wang L, Chen W, Wu R (2019) Time-varying contribution of internal dynamics to wintertime land temperature trends over the Northern Hemisphere. Geophys Res Lett 46:14674-14682

Goyal R, Gupta AS, Jucker M, England MH (2021) Historical and projected changes in the Southern Hemisphere Surface Westerlies. Geophys Res Lett 48:e2020GL090849. https://doi.org/10.1029/2020G L090849

Hersbach H et al (2020) The ERA5 global reanalysis. Q J R Meteorol Soc 146(730):1999-2049. https://doi. org/10.1002/qj.3803

Hildebrand FB (1956) Introduction to numerical analysis. McGraw-Hill Book Company, INC., New York, p 511

Holmes CR, Woollings T, Hawkins E, De Vries H (2016) Robust future changes in temperature variability under greenhouse gas forcing and the relationship with thermal advection. J Clim 29:2221-2236

Hsu SA, Meindl EA, Gilhousen DB (1994) Determining the power-law wind-profile exponent under nearneutral stability conditions at sea. J Appl Meteorol Climatol 33(6):757-765

Hu K, Huang G, Xie SP (2019) Assessing the internal variability in multi-decadal trends of summer surface air temperature over East Asia with a large ensemble of GCM simulations. Clim Dyn 52:6229-6242

Hueging H, Haas R, Born K, Jacob D, Pinto JG (2012) Regional changes in wind energy potential over Europe using regional climate model ensemble projections. J Appl Meteorol Climatol 52:903-917 
Karnauskas KB, Lundquist JK, Zhang L (2018) Southward shift of the global wind energy resource under high carbon dioxide emissions. Nat Geosci 11:38-43. https://doi.org/10.1038/s41561-017-0029-9

Kay J et al (2015) The Community Earth System Model (CESM) large ensemble project: A community resource for studying climate change in the presence of internal climate variability. Bull Amer Meteor Soc 96:1333-1349. https://doi.org/10.1175/BAMS-D-13-00255.1

Kim J, Paik K (2015) Recent recovery of surface wind speed after decadal decrease: a focus on South Korea. Clim Dyn 45:1699-1712. https://doi.org/10.1007/s00382-015-2546-9

Klink K (1999) Trends in mean monthly maximum and minimum surface wind speeds in the coterminous United States, 1961 to 1990 . Clim Res 13:193-205

Kumar D, Mishra V, Ganguly AR (2014) Evaluating wind extremes in CMIP5 climate models. Clim Dyn 45:441-453

Lai Y, Chen X, Ma Y, Chen D, Zhaxi S (2021) Impacts of the westerlies on planetary boundary layer growth over a valley on the north side of the central Himalayas. J Geophys Res 126:e2020JD033928. https://doi.org/10.1029/2020JD033928

Lange S (2019) Trend-preserving bias adjustment and statistical downscaling with ISIMIP3BASD (v1.0). Geosci Model Dev 12:3055-3070. https://doi.org/10.5194/gmd-12-3055-2019

McVicar TR, Roderick ML (2010) Atmospheric science: winds of change. Nat Geosci 3(11):747-748

McVicar TR et al (2008) Wind speed climatology and trends for Australia, 1975-2006: capturing the stilling phenomenon and comparison with near-surface reanalysis output. Geophys Res Lett 35:L20403. https://doi.org/10.1029/2008GL035627

McVicar TR et al (2010) Observational evidence from two mountainous regions that near-surface wind speed are declining more rapidly at higher elevations than lower elevations: 1960-2006. Geophys Res Lett 37:L06402. https://doi.org/10.1029/2009GL042255

McVicar TR et al (2012) Global review and synthesis of trends in observed terrestrial near-surface wind speeds: Implications for evaporation. J Hydrol 416(417):182-205. https://doi.org/10.1016/j.jhydrol. 2011.10.024

Meehl GA, Tebaldi C (2004) More intense, more frequent, and longer lasting heat waves in the 21st century. Science 305:994-997

Moemken J, Reyers M, Feldmann H, Pinto JG (2018) Future changes of wind speed and wind energy potentials in EURO-CORDEX ensemble simulations. J Geophys Res Atmos 123:6373-6389. https://doi.org/10.1029/2018JD028473

North GR, Moeng FJ, Bell TJ, Cahalan RF (1982) Sampling errors in the estimation of empirical orthogonal functions. Mon Wea Rev 110:699-706

Peixoto J, Oort A (1992) The physics of climate. AIP, NY, p 520

Pryor SC, Barthelmie RJ (2010) Climate change impacts on wind energy: a review. Renew Sustain Energy Rev 14:430-437

Pryor SC, Schoof JT (2010) Importance of the SRES in projections of climate change impacts on nearsurface wind regimes. Meteorol Z 19:267-274

Pryor SC, Schoof JT, Barthelmie RJ (2006) Winds of change?: Projections of near-surface winds under climate change scenarios. Geophys Res Lett 33:L11702. https://doi.org/10.1029/2006GL026000

Pryor SC et al (2009) Wind speed trends over the contiguous United States. J Geophys Res Atmos 114:D14105

Ramon J et al (2019) What global reanalysis best represents near-surface winds? Q J R Meteorol Soc 145(724):3236-3251. https://doi.org/10.1002/qj.3616

Reyers M, Moemken J, Pinto JG (2016) Future changes of wind energy potentials over Europe in a large CMIP5 multi-model ensemble. Int J Climatol 36:783-796

Sillmann J, Kharin VV, Zwiers FW, Zhang X, Bronaugh D (2013) Climate extremes indices in the CMIP5 multimodel ensemble: Part 1. Model evaluation in the present climate. J Geophys ResAtmos 118:1716-1733

Sillmann J et al (2017) Understanding, modeling and predicting weather and climate extremes: Challenges and opportunities. Wea Clim Ext 18:65-74

Solomon S et al (2007) Climate Change 2007. The physical science basis: working group i. Contribution to the Fourth Assessment Report of the IPCC. Cambridge University Press, Cambridge, p 996

Swart NC et al (2019) The Canadian Earth System Model version 5 (CanESM5.0.3). Geosci Model Dev 12:4823-4873

Thompson DWJ, Wallace JM (1998) The Arctic oscillation signature in wintertime geopotential height and temperature fields. Geophys Res Lett 25:1297-1300

Torrabla V, Doblas-Reyes FJ, Gonzalez-Reviriego N (2017) Uncertainty in recent near-surface wind speed trends: a global reanalysis intercomparison. Environ Res Lett 12:114019 
Vautard R et al (2010) Northern Hemisphere atmospheric stilling partly attributed to an increase in surface roughness. Nat Geosci 3:756-761

Vose RS et al (2014) Monitoring and understanding changes in extremes: extratropical storms, winds, and waves. Bull Amer Meteor Soc 95:377-386

Wallace JM, Gutzler DS (1981) Teleconnections in the geopotential height field during the Northern Hemisphere Winter. Mon Wea Rev 109:784-812

Wallace JM, Deser C, Smoliak BV, Phillips AS (2014) Attribution of climate change in the presence of internal variability. In: Chang CP (ed) Climate Change: Multidecadal and Beyond, vol 6. AsiaPacific Weather and Climate Series. World Scientific, Singapore, pp 1-29

Wu J, Zha J, Zhao D, Yang Q (2018) Changes in terrestrial near-surface wind speed and their possible causes: an overview. Clim Dyn 51:2039-2078

Yu B, Lin H, Kharin VV, Wang XL (2019) Interannual variability of North American winter temperature extremes and its associated circulation anomalies in observations and CMIP5 simulations. J Clim. https://doi.org/10.1175/JCLI-D-19-0404.1

Yu B, Li G, Chen S, Lin H (2020) The role of internal variability in climate change projections of North American surface temperature and temperature extremes in CanESM2 large ensemble simulations. Clim Dyn 55:869-885. https://doi.org/10.1007/s00382-020-05296-1

Yu B, Li G, Lin H, Chen S (2021) Projected trends of wintertime North American surface mean and extreme temperatures over the next half century in two generations of Canadian Earth System Models. Atmos Ocean 59:53-75. https://doi.org/10.1080/07055900.2021.1879726

Zeng $\mathrm{Z}$ et al (2019) A reversal in global terrestrial stilling and its implications for wind energy production. Nat Clim Chang 9:979-985. https://doi.org/10.1038/s41558-019-0622-6

Publisher's note Springer Nature remains neutral with regard to jurisdictional claims in published maps and institutional affiliations. 